\title{
Correction to: Unilateral duplicated abducens nerve coursing through both the sphenopetroclival venous gulf and cavernous sinus: a case report
}

\author{
Thomas Coquet $^{1} \cdot$ Michel Lefranc $^{1,2} \cdot$ Louis Chenin $^{1} \cdot$ Pascal Foulon $^{1} \cdot$ Éric Havet $^{1}$ - Johann Peltier ${ }^{1,2}$
}

Published online: 28 August 2018

(c) Springer-Verlag France SAS, part of Springer Nature 2018

\section{Correction to: \\ Surgical and Radiologic Anatomy (2018) 40:835-840 https://doi.org/10.1007/s00276-018-2003-7}

In the Original Publication of the article, one of the references was missed to include, leading to an error in citation. This reference and the text citation are given below.

\section{Missing reference:}

24. Wysiadecki G, Polguj M, Topol M (2016) An unusual variant of the abducens nerve duplication with two nerve trunks merging within the orbit: a case report with comments on developmental background. Surg Radiol Anat 38:625-629
Erratum: page 839, Discussion, Morphogenesis of the petrosphenoidal gulf and the cavernous sinus, second paragraph, lines 1-8:

Peng et al. [17] and Wysiadecki et al. [24] speculated that the lateral rectus muscle may comprise two functionally distinct compartments, resulting in two "targets" for the growing nerve fibers. The AN duplication may result from "alternative developmental pathways in which this nerve's axons, specific for a given segment of the lateral rectus muscle, run separately at some stage instead of forming a single nerve" [24].

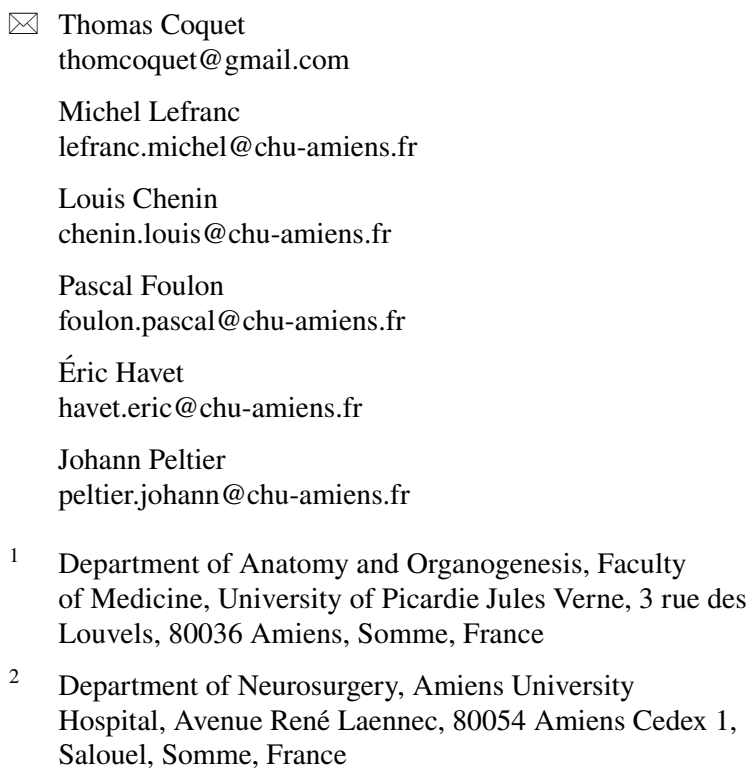

